\title{
Impact of strategic capabilities on organizational ambidexterity in the commercial banks in Jor- dan: The mediating role of knowledge management
}

\author{
Riad Ahmad Mohammed Abazeed ${ }^{\mathrm{a}^{*}}$
}

${ }^{a}$ Associate Professor of Business Management and Public Administration, Department of Business Administration, Faculty of Finance and Business Administration, Al al-Bayt University, P.O.BOX 130040, Mafraq 25113, Jordan

\section{CH R O N I C E A B T RACT}

Article history:

Received: November 12, 2019

Received in revised format: November 302019

Accepted: December 18, 2019

Available online:

December 19, 2019

Keywords:

Strategic Capabilities

Organizational Ambidexterity

Knowledge Management

Commercial banks

Jordan

\begin{abstract}
This study seeks to explain the impact of strategic capabilities on organizational ambidexterity, in the presence of knowledge management. The study population consists of managers of commercial banks in Jordan. The sample included (200) respondents by distributing the study questionnaires to them, where the returned questionnaires and valid to statistical analysis were (168). Structural equation modelling (SEM) was used as an inferential statistical analysis technique to test the hypotheses of the study. The result of this study referred that knowledge management mediates the relationship between strategic capabilities and organizational ambidexterity. Hence, all dimensions of strategic capabilities (marketing capability, market-linking capability, technology capability, and management capability) have a statistical impact on both knowledge management dimensions (knowledge acquisition, knowledge creation, knowledge application, and knowledge storage) and the dimensions of organizational ambidexterity (exploitation and exploration). Therefore, the study recommends managers and decision-makers of commercial banks in Jordan to focus on strategic capabilities that enhance their abilities to identify and acquire opportunities from the business environment by building good relationships with both customers and suppliers. Besides, improving their employees' capacity to deal with new knowledge and apply it to create novel products and services.
\end{abstract}

\section{Introduction}

Organisations continually need to develop new products and services to cope with the complexity and rapid changes in business environments (Xinwei et al., 2018). These changes require the ability of organisations to integrate and reconfigure both internal and external resources and skills that are harmony with the business environment to adopt optimal strategies in order to achieve long horizon goals (Adil et al., 2015; O'Reilly \& Tushman, 2008). Therefore, organisational ambidexterity is providing as one of the critical strategies that help the organisations restructure their resources by exploration the opportunities from the business markets and exploitation them to improve managerial skills which lead to enhance the organisations' performance (Lubatkin et al., 2006). Since the researchers have been considering the organisational ambidexterity that classified in the strategic domain to face aggressive competition in the market (O'Reilly \& Tushman, 2013), this requires of organisations thinking to acquire and maintain a set of specific skills and abilities to achieve their goals (Lee et al., 2017). Hence, organisations are emphasising on analysing strategic capabilities to identify their critical intangible resources, how to deploy these resources within an organisation and orienting them to increase their competitive performance (Agyapong et al., 2016; Seyhan et al., 2017). Besides, organisations' management realised the vital role of knowledge as an essential resource to support their activities and enable employees to think creatively, which help to gain long term advantages of an organisation

* Corresponding author.

E-mail address: riad.abazeed2018@gmail.com (R. A. M. Abazeeda) 
(Alavi \& Leidner, 2001). Thus, they focused on methodologies and methods to manage their organisations' knowledge acquired from the external environment or generated internally (Alias et al., 2018; Wenger et al., 2002). Proper knowledge management helps to choose the optimal strategy, as well as support decision-making processes that influence on the organisation's outcomes (Al-Hawary \& Alwan, 2016). Furthermore, it can enhance the employees' ability to create new products and services which enable an organisation to enter new markets or increase market share (Abuzyead \& Sherif, 2017; Donate \& Sánchez de Pablo, 2015; Malkawi \& Rumman, 2016). Accordingly, this study investigates the relationship between strategic capabilities and organisational ambidexterity, as well as the mediating role of knowledge management in this relationship.

\section{Theoretical Framework}

\subsection{Strategic Capabilities}

Organisations need diverse interrelated capabilities in all organisational functions to create value for it, where these capabilities difference between organisations according to a lot of internal and external factors (Di Benedetto \& Song, 2003). The organisation's capabilities were classified in the second level of competencies hierarchy, where they link between an organisation's resources and competencies, which express an organisation's intangible resources (Čirjevskis, 2019; Javidan, 1998). Organisations seek to incentive building the competitive advantage and growth in the long term by recognising their fundamental capabilities and develop them into strategic capabilities (Seyhan et al., 2017; Teece, 2014). The concept of strategic capabilities is linking with the resource-based view (RBV), where both perspectives focusing on developing the core competencies that cannot be imitated by rivals. Further, the necessitate of optimal use the tangible and intangible organisational resources (Carraresi et al., 2012; Hoon Jang, 2013; Takahashi \& Sander, 2017). The term of strategic capabilities was defined as the intricate accumulative knowledge and skills of the organisations which enable them to coordinate their processes and reconfigure their assets to generate economic value and attain sustainable competitive advantage (Day, 1994). Besides Lado et al. (1992) referred to strategic capabilities as the unique internal skills and operations that the organisation owned but not available to its competitors. Moreover, Johnson et al. (2017) argued that strategic capabilities are the specific organisation resources and competencies that contribute to identifying their appropriate strategies in order to achieve superior performance of the organisation. To determine the strategic capabilities in the organisations, researchers suggested four dimensions according to (Isfahani et al., 2012; Parnell, 2011; Seyhan et al., 2017; Spillan et al., 2018), these dimensions are marketing capability, market linking capability, technology capability, and management capability. While DeSarbo et al. (2005), Hao and Song (2016) and Kimosop et al. $(2015,2016)$ added one more dimension is information technology capability in order to measure strategic capabilities. In this research, strategic capabilities are measured by four dimensions (Parnell, 2011; Seyhan et al., 2017; Spillan et al., 2018; Isfahani et al., 2012). Marketing capability refers to the skills used in marketing activities which includes market segmentation, determine the target market, pricing the products and services and promotion activities (Seyhan et al., 2017). Furthermore, integrate the marketing activities effectively by creating both customers and rivals databases to cope with continuously changing in the organisation's environment (DeSarbo et al., 2005). Market Linking Capability focuses on sensing the environmental factors which influence the organisation's ability to cope with changed customers' needs, as well as communication processes between different channels (Kimosop et al., 2016), this capability can help the organisations build customers' loyalty by quick forecasting then responding effectively to their customers' needs (Day, 1994; Seyhan et al., 2017). Organisations aim abreast of new developments by the emphasis on available technology capability in the markets. Hence, they heavily invest in this capability that enables them to enhance R\&D operations and provide new products and services to rapidly face customers' expectations, besides offering superior products and services to overcome their competitors (Hao \& Song, 2016). Management capability provides support to all previous capabilities, where its rationalisation organisational structures and activities by rising the organisation's flexibility and decrease uncertainty (Raymond et al., 2010). Management capability also influences the organisation's competitive advantage through adopting a unique set of managerial functions and skills which enables it to make strategic decisions that lead success in using its resources (Seyhan et al., 2017).

\subsection{Organisational Ambidexterity}

Driven by the idea that organisations are seeking to meet the rising capabilities of markets, they continually differentiate between the mechanisms of exploiting available resources and the competitive priorities of survival in markets according to a set of criteria (Moran \& Ghoshal, 1996). Hence, organisations require a group of unique capabilities, structures, and leadership patterns to achieve a level of ambidexterity balancing between short and long term goals (Birkinshaw \& Gupta, 2013). The organisations should frequently recreate themselves, especially in rapidly changing environments, in order to achieve organisational adaptation which considers a necessitate for success in the long term (Ahuja \& Morris Lampert, 2001; Bower \& Paine, 2017; Kotter, 1996). Organisational ambidexterity has been proposed as a critical matter for organisations for the organisational success and excellent performance in the short and long horizon (Birkinshaw \& Gupta, 2013; O'Reilly \& Tushman, 2013). Organisational ambidexterity was discussed in a lot of researches. Accordingly, Rothaermel and Deeds (2004) indicated to this concept as "a dynamic capability by which organizations mobilize, coordinate, and integrate dispersed contradictory efforts, and allocate, combine and recombine resources and assets across differentiated exploratory and exploitive units". Also, Peng et al. (2019) referred to organisational ambidexterity as the capacity to follow exploration and exploitation in the business environments. Thus, most researchers adopted two dimensions to measure organisational ambidexterity, these dimensions are exploration and exploitation (Fu et al., 2016; Hughes, 2018; Lee et al., 2017; O’Reilly \& Tushman, 2013; Panagopoulos, 2016; Peng et al., 2019; Sulphey, 2019). Exploration is the organisation orientation to discover 
new ideas and optimal opportunities that can enhance the ability to innovate (Sulphey, 2019). It also emphasises on generating radical innovations that can compose long-term the organisation's future by existing products and activities that undermine to do so (Hughes, 2018). While, exploitation is reconfiguring the organisation's resources and knowledge that can improve their efficiency (Sulphey, 2019). Exploitation also presents a dynamic capability depending on path-based learning and knowledge accumulation, where the organisations seek for development of the existing skills and expand into new markets (Peng et al., 2019).

\subsection{Knowledge Management}

Knowledge management is a comparatively new orientation in the business field, where this term has become critical for the organisation for the survival and enhance of their capabilities in order to stay and develop their competitiveness position (Abbas \& Sağsan, 2019). Knowledge management has provided through four views: the philosophic view that explains the origin of knowledge, the organisational development view which identifies mechanisms that enable to create and mastering knowledge together, the business view that based on value generation by available knowledge, and the technological view that determines the most effective methods and tools to usefully of knowledge (Bernard Nielsen, 2005). Accordingly, the definitions related to knowledge management varied based on researcher perspective. Gilaninia et al. (2013) provided one of the definitions of knowledge management as a group of operations that aimed to convert intangible intellectual resources into tangible values. Al-Hawary and Alwan (2016) referred it as "a set of processes and activities carried out by the management of organizations to determine the required knowledge and find it, and keep track of the different managerial methods that help on it is management, to invest effectively to create added value to their activities and operations to achieve competitive advantage, and provide an opportunity to survive in an environment characterized by major change and development". While Ghaffari et al. (2012) noticed that knowledge management expresses an attempt to increase and enhance the usage of knowledge within an organisation through acquisition, sharing, and storage knowledge.

This research uses four dimensions of knowledge management, which are knowledge creation, knowledge application, knowledge transfer, and knowledge storage (Donate and Sánchez de Pablo, 2015; Khyzer Bin Dost et al., 2018; Novak, 2017; Torabi et al., 2016). Knowledge creation indicates to the organisation's ability to discover and develop new idea and arrangements in different organisational activities (Alias et al., 2018). Also, it considers a critical factor to enable both organisation and their employees in order to improve skills and capabilities in the turbulent business environment (Eisenhardt \& Martin, 2000; Scharmer, 2001). Knowledge application refers to generate value for the organisation dependent on activate knowledge usage through various methods such as repackaging knowledge, training, and motivating their employees to think innovatively (Mills \& Smith, 2011; Novak, 2017). While knowledge transfer is considered as mechanisms to dissemination and sharing of knowledge within the organisation's employees and departments (Alias et al., 2018; King, 2007). Moreover, it is a multidisciplinary procedure and specialised tools and methodologies, where the human resource deems the main factor in getting the best effective organisational outcomes (Trivellas et al., 2015). Finally, knowledge storage is the activities related to recording, arranging, and displaying knowledge that considered as one of the most essential accumulated assets for the organisation (Cummings \& Teng, 2003; Khyzer Bin Dost et al., 2018), where it enables the organisation to the retention of knowledge and enhance the organisation's memory by generating a shared database which collects acquired knowledge from different departments (Novak, 2017; Obeidat et al., 2016).

\subsection{Hypotheses development \\ 2.4.1 Strategic Capabilities and Organisational Ambidexterity}

Organisation's sustainable competitive advantage reaches from both internal resources that owned and how the organisation integrates and convert these resources through suitable organisational capabilities, as well as the intangible external resources which can be shaped into internal capital (Teece, 2014). Strategic capabilities are focusing on the rapid adoption of vital resources that lead to improving innovation activities in response to business environment changes (Yu et al., 2014), it enables to expand an organisation's vision about sector developments and acquired external resources (Cheah et al., 2019), encourage to long term development by reconfiguration an organisation's resources (Čirjevskis, 2019), and it is responsible for maintaining competitive performance, as well as plays a critical role in organisation's strategic choice-making (Shimizu \& Hitt, 2004). Moreover, strategic capabilities enhance the expansion of knowledge, information, and resources that lead organisations to explore market opportunities (Xinwei et al., 2018). Besides, they enable us to improve organisation's ability of exploitation these opportunities by adopting the exploitative innovation strategy that ensures the full utilisation of organisation potential (Guo, 2019; Salunke et al., 2019). Hence, the first hypothesis describes this relation as follow:

H1: There is a statistically significant impact of strategic capabilities on organisational ambidexterity.

\subsubsection{Strategic Capabilities and Knowledge Management}

The idea of strategic capabilities emerges as a supplement of the resource-based view that is broadly focused on an organisation's resources, whether tangible or intangible to gain and maintain the competitive advantage (Carraresi et al., 2012; Takahashi \& Sander, 2017). Knowledge management is more harmonic with the knowledge-based theories, which mainly emphasise on the stock of knowledge on the organisation, determining the required knowledge typologies, and the best methods to manage the knowledge (Alavi \& Leidner, 2001; Baskerville \& Dulipovici, 2006; Tzortzaki\& Mihiotis, 2014). Indeed, the dynamic environments stimulate the organisations to identify the required knowledge to execute the strategic goals and 
comparing them with existing knowledge in order to find strategic knowledge gaps then directing their capabilities to fill these gaps (Ramadan et al., 2017). Hence, strategic capabilities which deem as the abilities to cope with interactive markets by utilising the organisation's resources in optimal ways lead to building internal knowledge through motivating on sharing skills and knowledge, as well as acquiring external knowledge by sensing the knowledge and seeking to earn it (Assudani, 2008; Takahashi \& Sander, 2017). Accordingly, the second hypothesis formulated as follow:

$\mathrm{H} 2$ : There is a statistically significant impact of strategic capabilities on knowledge management.

\subsubsection{Knowledge Management and Organisational Ambidexterity}

Organisations tend toward homogeneity during developing mindsets and routines to support one of the innovation forms (Smith \& Tushman, 2005). Leveraging existing capabilities may enable to gain rapid profits but leads eventual stagnation as a result of market and technological changes (Atuahene-Gima, 2005). Therefore, organisational ambidexterity is estimated as a method to manage the organisations' resources in order to face these challenges by create supporting structures, strategies, and contexts enable of exploration then exploitation the opportunities (O'Reilly \& Tushman, 2013; Panagopoulos, 2016; Smith \& Tushman, 2005). An effective exploration and exploitation processes require harnessing current knowledge capabilities, as well as searching on new and various knowledge (Hill \& Jones, 2010; Rothaermel \& Deeds, 2004; Yuliansyah, 2018). Indeed, knowledge management is considered a vital factor in providing innovative products and services which enable the organisation to cope their rivals through creating new knowledge, sharing and application the knowledge in production and supporting activities, moreover storage this knowledge to utilise it to the adaptation of business environments (Wadhwa \& Kotha, 2006). Therefore, the third hypothesis refers to:

H3: There is a statistically significant impact of knowledge management on organisational ambidexterity.

\subsubsection{Strategic Capabilities, Knowledge Management, and Organisational Ambidexterity}

The resource-based view and strategic capability emphasised that the development of distinctive characteristics enable organisations to defy competitive imitation (Khan, 2018). The dynamic capabilities approach suggested that the organisation's resources are developing during life cycle stages from growth to dissolution (Helfat and Peteraf, 2009). Indeed, the dynamic capabilities approach has expanded the strategic capabilities perspective through focusing on the temporary nature of both the organisation's resources and external effects (Barros et al., 2016; Pervan et al., 2018). The importance of strategic capabilities demonstrates from enabling an organisation to sense available opportunities in the markets, besides exploitation the needed resources in order to snatch these opportunities from competitors (Zgarni, 2019). Furthermore, knowledge management can help to enhance the exploitation and exploration knowledge that lead to creating novel products and services (Santoro et al., 2019). Also, strategic capabilities contribute to building an intensive knowledge environment by identifying and acquiring the necessary knowledge from the external environment and transfer it into the internal organisation's environment to apply this knowledge for producing innovative products and services (Dimitriades, 2005). Accordingly, the fourth hypothesis indicates:

H4: There is a statistically significant impact of strategic capabilities on organisational ambidexterity through knowledge management.

\section{Methodology}

\subsection{Research population and sample}

The population of this research consists of managers of commercial banks in Jordan. The unit of the study is top and middle level managers of commercial banks in Jordan. A convenience sample was selected to represent the population. 200 questionnaires were distributed to the study sample. 168 questionnaires returned valid for statistics. Table 1 presents the characteristics of the study sample.

Table 1

Characteristics of the study sample

\begin{tabular}{|c|c|c|c|}
\hline Variable & & Frequency & $\%$ \\
\hline \multirow[t]{4}{*}{ Age group } & less than 30 & 2 & $1.2 \%$ \\
\hline & 30 - less than 40 & 64 & $38.1 \%$ \\
\hline & 40 - less than 50 & 77 & $45.8 \%$ \\
\hline & 50 years and more & 25 & $14.9 \%$ \\
\hline \multirow[t]{2}{*}{ Gender } & Male & 122 & $72.6 \%$ \\
\hline & Female & 44 & $27.4 \%$ \\
\hline \multirow[t]{4}{*}{ Educational level } & Diploma & 2 & $1.2 \%$ \\
\hline & Bachelor & 123 & $73.2 \%$ \\
\hline & Master & 35 & $20.8 \%$ \\
\hline & $\mathrm{PhD}$ & 8 & $4.8 \%$ \\
\hline
\end{tabular}




\subsection{Research conceptual model}

Relationships outlined in Fig. 1 limn four hypothesized impacts between three constructs, which are strategic capabilities, knowledge management and organisational ambidexterity. The construct escorted by four dimensions of capabilities is the exogenous one, while the construct measured by exploration and exploitation is the endogenous one. What's more is that the effect of strategic capabilities on organisational ambidexterity was examined in terms of its both direct and indirect effect without/with the presence of knowledge management as a mediating variable.

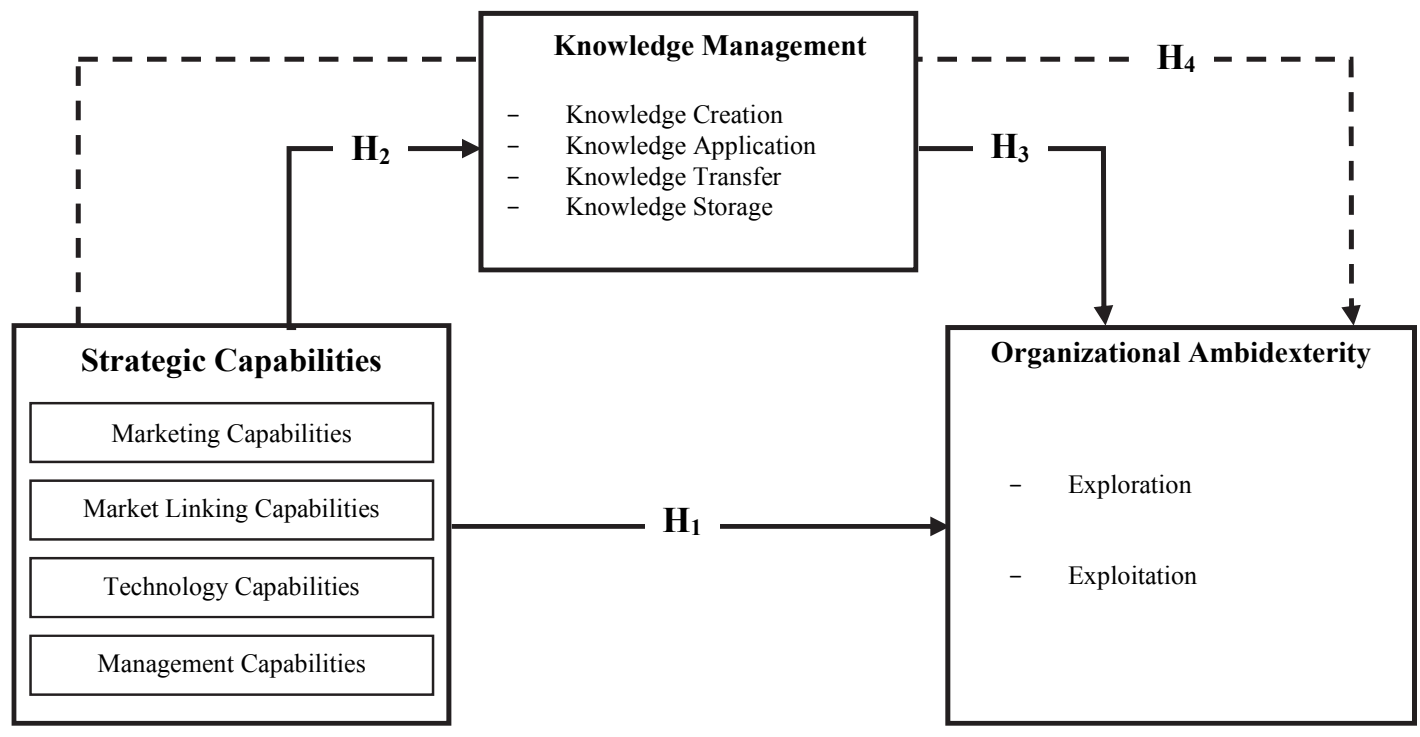

Fig. 1. Research theoretical model

\subsection{Research instrument}

Strategic capabilities (SC) as a whole predictor variable was rated using four dimensions, which were marketing, market linking, technology, and management capabilities, while organisational ambidexterity (OA) as a whole response variable was scored using two dimensions exploration and exploitation. Concurrently, knowledge management (KM) was estimated using four key practices, which were knowledge creation, application, and transfer along with storage. The instrument was designed in accordance with five-point Likert scale. Items used to gauge these variables are divulged in Table 2.

Table 2

Items used to measure research variables

\begin{tabular}{|c|c|c|c|}
\hline Variables & Dimensions & No. of Items & Cronbach's alpha * \\
\hline \multirow{4}{*}{$\mathrm{SC}$} & Marketing capabilities & 4 & 0.87 \\
\hline & Market linking capabilities & 5 & 0.82 \\
\hline & Technology capabilities & 5 & 0.86 \\
\hline & Management capabilities & 4 & 0.81 \\
\hline \multirow{2}{*}{$\mathrm{OA}$} & Exploration & 4 & 0.77 \\
\hline & Exploitation & 3 & 0.79 \\
\hline \multirow{4}{*}{ KM } & Knowledge creation & 3 & 0.83 \\
\hline & Knowledge application & 4 & 0.87 \\
\hline & Knowledge transfer & 3 & 0.81 \\
\hline & Knowledge storage & 3 & 0.79 \\
\hline
\end{tabular}

* Computed on the ground of a pilot study conducted on 50 subjects outside the original sample

Cronbach's alpha coefficients delineated in Table 2 ratify the decision upon which the initial version of the questionnaire was regarded as an appropriate instrument. Hence, the instrument was distributed to the original sample. Accrued data on the ground of that questionnaire were subjected to exploratory factor analysis (EFA).

\subsection{Exploratory factor analysis (EFA)}

The aim of using EFA was to assess the factor structure so as common items between all variables constitute a single factor (Florescu et al., 2019). The main idea is to deduce the patterns of factor loadings (Amornpipat, 2019). The results of EFA are proclaimed in Table 3. Based on Deng (2010, cited in Amornpipat, 2019), an item with factor loading no greater than 0.4 was 
removed. In the current study 5 items were deleted due to factor loadings lower than 0.4 (Sleimi, 2020). Principally, eigenvalues of factors above 1 explained about $73.1 \%$ (Le et al., 2020).

It was established that the application of EFA resulted in 4 indicators for marketing capabilities (MRC1- MRC4), 4 indicators for market linking capabilities (MLC1-MLC4), in addition to 4 items for technology capabilities (TEC1-TEC4) and 3 items for Management capabilities (MTC1-MTC3). For OA dimensions, both exploration and exploitation were interpreted using 3 indicators; EXR1-EXR3 and EXL1-EXL3, respectively. KM, on the other hand, had 4 dimensions with 12 items distribute equally among knowledge creation (KCR1-KCR3), application (KAP1-KAP3), transfer (KTR1-KTR3) and storage (KSG1KSG1). All factor loadings of those indicators met the required cut-off criterion, which assumes that these loadings should be no less than 0.5 (Le et al., 2020). Figures that came into view in Table 3 were used to appraise instrument reliability and validity. Cronbach's alpha coefficient $(\alpha)$ as an indicator of instrument internal consistency was used to judge reliability while average variance extracted (AVE) was utilized as an index of convergent validity. Cronbach's alpha coefficients were higher than 0.7 and values of the average variance inflation (AVE) were greater than 0.5 (Thaib, 2020).

Table 3

EFA results and descriptive

\begin{tabular}{|c|c|c|c|c|c|c|c|}
\hline Dimensions & Items & SFL & Means & SDs & AVE & $\mathbf{C R}$ & $\alpha$ \\
\hline \multirow{4}{*}{ Marketing capabilities } & MRC1 & 0.78 & \multirow{4}{*}{3.71} & \multirow{4}{*}{0.89} & \multirow{4}{*}{0.649} & \multirow{4}{*}{0.881} & \multirow{4}{*}{0.862} \\
\hline & MRC2 & 0.81 & & & & & \\
\hline & MRC3 & 0.84 & & & & & \\
\hline & MRC4 & 0.79 & & & & & \\
\hline \multirow{4}{*}{ Market linking capabilities } & MLC1 & 0.89 & \multirow{4}{*}{3.61} & \multirow{4}{*}{0.97} & \multirow{4}{*}{0.727} & \multirow{4}{*}{0.914} & \multirow{4}{*}{0.891} \\
\hline & MLC2 & 0.85 & & & & & \\
\hline & MLC3 & 0.83 & & & & & \\
\hline & MLC4 & 0.84 & & & & & \\
\hline \multirow{4}{*}{ Technology capabilities } & TEC1 & 0.78 & \multirow{4}{*}{3.63} & \multirow{4}{*}{1.01} & \multirow{4}{*}{0.570} & \multirow{4}{*}{0.841} & \multirow{4}{*}{0.832} \\
\hline & TEC2 & 0.76 & & & & & \\
\hline & TEC3 & 0.75 & & & & & \\
\hline & TEC4 & 0.73 & & & & & \\
\hline \multirow{3}{*}{ Management capabilities } & MTC1 & 0.88 & \multirow{3}{*}{3.59} & \multirow{3}{*}{0.84} & \multirow{3}{*}{0.798} & \multirow{3}{*}{0.922} & \multirow{3}{*}{0.901} \\
\hline & MTC2 & 0.89 & & & & & \\
\hline & MTC3 & 0.91 & & & & & \\
\hline \multirow{3}{*}{ Exploration } & EXR1 & 0.72 & \multirow{3}{*}{3.55} & \multirow{3}{*}{0.91} & \multirow{3}{*}{0.627} & & \\
\hline & EXP2 & 0.79 & & & & 0.834 & 0.827 \\
\hline & EXP3 & 0.86 & & & & & \\
\hline & EXL1 & 0.81 & & & & & \\
\hline Exploitation & EXL2 & 0.83 & 3.49 & 0.88 & 0.684 & 0.866 & 0.864 \\
\hline & EXL3 & 0.84 & & & & & \\
\hline & KCR1 & 0.85 & & & & & \\
\hline Knowledge creation & $\mathrm{KCR} 2$ & 0.83 & 3.62 & 1.11 & 0.695 & 0.872 & 0.868 \\
\hline & KCR3 & 0.82 & & & & & \\
\hline & KAP1 & 0.92 & & & & & \\
\hline Knowledge application & KAP2 & 0.86 & 3.58 & 0.74 & 0.753 & 0.901 & 0.897 \\
\hline & KAP3 & 0.82 & & & & & \\
\hline & KTR1 & 0.82 & & & & & \\
\hline Knowledge transfer & KTR2 & 0.86 & 3.61 & 0.76 & 0.759 & 0.904 & 0.889 \\
\hline & KTR3 & 0.93 & & & & & \\
\hline & KSG1 & 0.94 & & & & & \\
\hline Knowledge storage & KSG2 & 0.86 & 3.65 & 0.85 & 0.776 & 0.912 & 0.896 \\
\hline & KSG3 & 0.84 & & & & & \\
\hline
\end{tabular}

In terms of means and standard deviations (SDs) of the constructs. The results in Table 3 indicate that the total degree of marketing capabilities was high $(\mathrm{M}=3.71, \mathrm{SD}=0.89)$. Degrees of the remaining dimensions of strategic capabilities, i.e., market linking capabilities $(\mathrm{M}=3.61, \mathrm{SD}=0.97)$, technology capabilities $(\mathrm{M}=3.63, \mathrm{SD}=1.01)$, and management capabilities $(\mathrm{M}=3.59, \mathrm{SD}=0.84)$ were moderate. Totally, the degree of strategic capabilities was moderate $(\mathrm{M}=3.64, \mathrm{SD}=0.66)$. Furthermore, the total degree of organisational ambidexterity was also moderate $(\mathrm{M}=3.52, \mathrm{SD}=0.58)$ with similar degrees for its dimensions; exploration $(\mathrm{M}=3.55, \mathrm{SD}=0.82)$ and exploitation $(\mathrm{M}=3.49, \mathrm{SD}=0.61)$. Finally, the total degree of knowledge management was moderate $(\mathrm{M}=3.62, \mathrm{SD}=0.73)$ reflecting similar degrees of its dimensions; knowledge creation $(\mathrm{M}=3.62, \mathrm{SD}=1.11)$, knowledge application $(\mathrm{M}=3.58, \mathrm{SD}=0.74)$, knowledge transfer $(\mathrm{M}=3.61, \mathrm{SD}=0.76)$, and knowledge storage $(\mathrm{M}=3.65, \mathrm{SD}=0.85)$.

\subsection{Confirmatory factor analysis (CFA)}

CFA was used after the model was specified using EFA, i.e., variables were loaded on the pre-specified factor in order to measure goodness-of-fit (GOF) for the specified model (Bismark et al., 2020). Fig. 2 parades the measurement model of the study. 


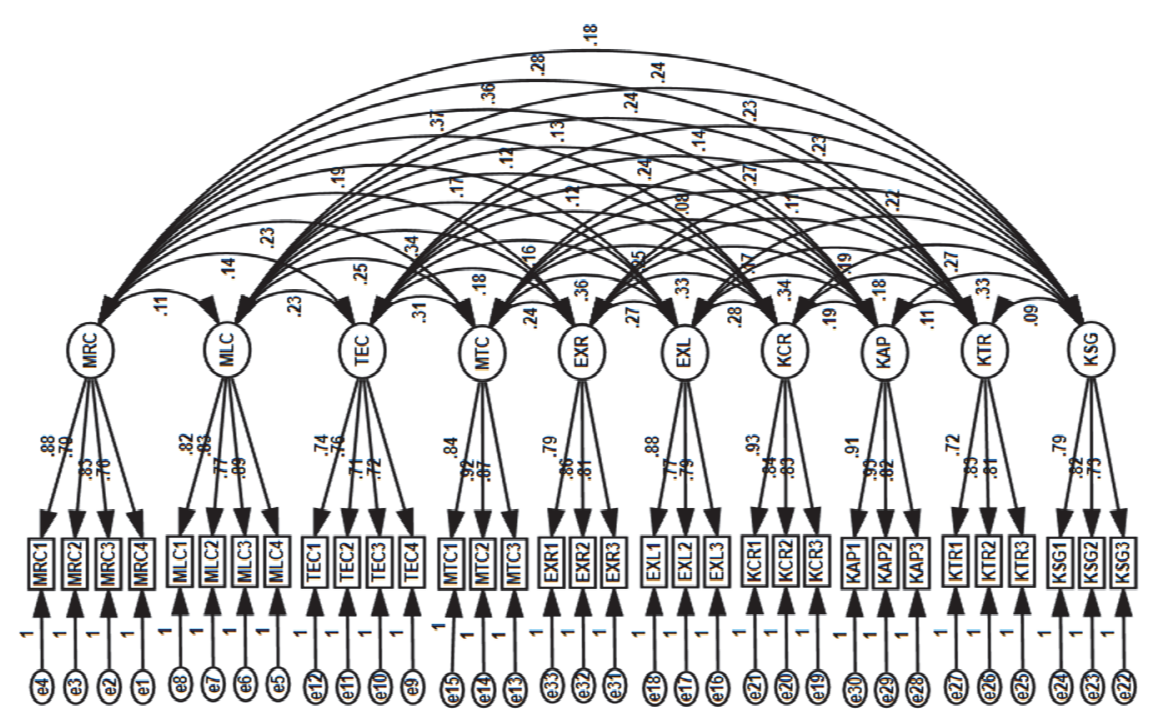

Fig. 2. Research measurement model

\subsection{Goodness-of-fit (GOF)}

Chi-squared/DF, goodness of fit index (GFI), comparative fit index (CFI) and root mean square error of approximation (RMSEA) are four examples of fit indices that can be used to evaluate the model goodness-of-fit (Alzoubi et al., 2020). Results of GOF indices in Table 4 indicated that the threshold values of these indices were met.

Table 4

GOF results

\begin{tabular}{|c|c|c|c|}
\hline Index & Value & Cut-off $*$ & Result \\
\hline Chi-square ratio (CMIN/DF) & 2.17 & $>3.00$ & Established \\
\hline Goodness of fit index (GFI) & 0.93 & $>0.90$ & Established \\
\hline Comparative fit index (CFI) & 0.94 & $>0.90$ & Established \\
\hline Root mean square error of approximation (RMSEA) & 0.07 & $<0.08$ & Established \\
\hline
\end{tabular}

* References: Subburaj et al. (2020); Lancia and Lulli (2020); Nangoy et al. (2020)

\subsection{Pearson correlation matrix}

Two aims were behind using Pearson correlation matrix. First, to examine that the current data are free of multicollinearity. According to Mustafa et al. (2020), data have no serious problem when correlation values among independent variables are less than 0.90 . that is the case, it was concluded that the current data are free of multicollinearity problem. In a study by Chiou and Chang (2020), correlation coefficients should be greater than 0.7, particularly for regression analysis. Additionally, variance inflation factor (VIF) and tolerance (Tol.) as indicators are used to investigate multicollinearity (Al-Natsheh \& Al-Okdeh, 2020). Correlation value, tolerance and VIF are shown in Table 5 in which tolerance $(>0.1)$ and VIF values $(<10)$ were found to be acceptable (Aries et al., 2020).

Table 5

Correlation matrix and multicollinearity indices

\begin{tabular}{|c|c|c|c|c|c|c|c|c|}
\hline & MRC & MLC & TEC & MTC & $\mathbf{K M}$ & OA & Tol. & VIF \\
\hline MRC & - & & & & & & 0.234 & 3.77 \\
\hline MLC & $0.34 * *$ & - & & & & & 0.351 & 3.89 \\
\hline TEC & $0.41 * *$ & $0.27 * *$ & - & & & & 0.521 & 4.12 \\
\hline MTC & $0.33 * *$ & $0.35^{*}$ & $0.53 * *$ & - & & & 0.367 & 5.26 \\
\hline KM & $0.36^{* *}$ & $0.46^{* *}$ & $0.61 * *$ & $0.42 * *$ & - & & 0.542 & 3.81 \\
\hline $\mathrm{OA}$ & $0.29 * *$ & $0.54 * *$ & $0.49 * *$ & $0.58 *$ & $0.63 *$ & - & 0.426 & 4.01 \\
\hline
\end{tabular}

On the basis of the above-reported findings, the final step of data analysis section includes an examination of the structural equation modelling (SEM) for hypothesis testing.

\subsection{Structural equation modelling (SEM)}

SEM was conducted using IBM SPSS AMOS 22.0 software. Scholars adopt as an approach in order to test their theoretical models and hypotheses (Ye et al., 2020). Fig. 3 exhibits research structural model. 
In light of the structural research model in Fig. 3, it was noted that the postulated hypotheses were verified. Results of hypotheses testing are shown in Table 6.

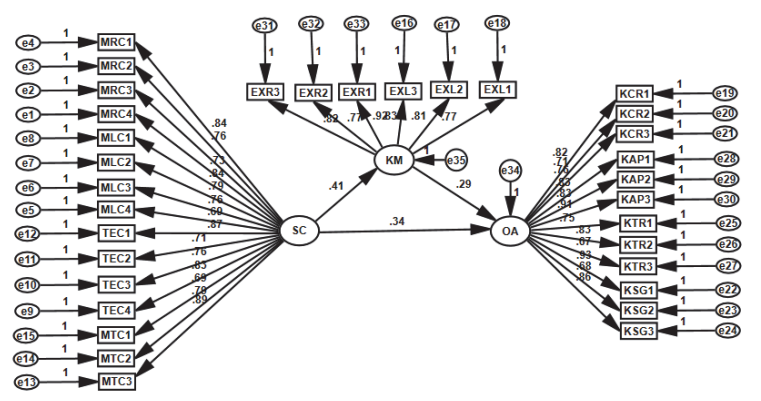

Fig. 32. Research structural model

Table 6

Hypotheses testing results

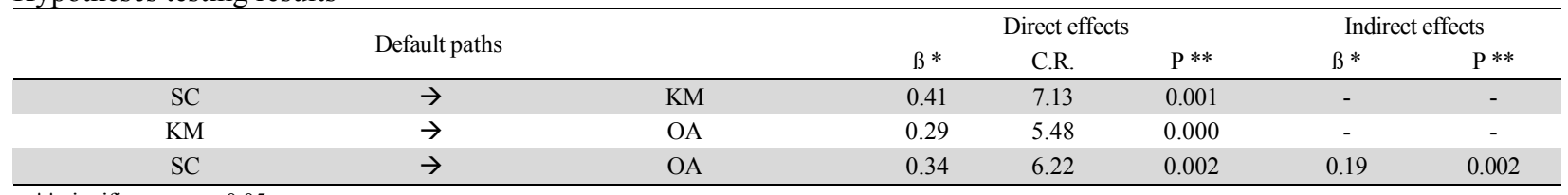

** significant at $\alpha=0.05$

According to the results, $\mathrm{SC}$ exerted a direct significant effect on $\mathrm{KM}(\beta=0.41, \mathrm{P}=0.001)$ as well as on $\mathrm{OA}(\beta=0.34, \mathrm{P}=$ 0.002). KM, in the same line show a significant direct effect on $\mathrm{OA}(B=0.29, \mathrm{P}=0.000)$. In addition, $\mathrm{SC}$ has an in direct effect on OA $(\beta=0.19, \mathrm{P}=0.002)$. These results, in fact, verified research hypothesis, in which strategic capabilities was presumed to predict organisational ambidexterity in the presence of knowledge management as a mediating variable.

\section{Results discussion}

This study aimed to examine the impact of strategic capabilities on organisational ambidexterity, as well as the mediating role of knowledge management between these variables. Hence, the result referred that strategic capabilities impact on organisational ambidexterity; this result agreed with Yu et al. (2014). Therefore, the organisation ability senses its business environment by utilising the networks built through the excellent relationship between the organisation and its customers, suppliers, and distribution channels. Thus, those networks can help the organisation increase their market share through targeting new customers by offering novel and creative products and services, as well as activating the technologies based on social media network to promote these products and services. Furthermore, the organisation ability to choose optimal strategies that enables it to acquire the best resources can convert to core competencies. Indeed, the core competencies recognised as the critical factor lead organisation to cope their rivals through continuously improving their products and services in order to face changeable customers' needs and wants and achieving sustainable competitive advantage. Also, the study result indicated that there is a significant effect of strategic capabilities on knowledge management, this result is consistent with other results (e.g. Assudani, 2008; Dimitriades, 2005; Santoro et al., 2019). Therefore, the organisation ability to create excellent customer and supplier relationship management by applying developed technologies enables the organisation to be followed with environmental changes providing innovative ideas. Those ideas can help organisations by converting them into creative products and services, as well as adopting new business models that lead to acquiring unique skills and experiences which accumulate at internally organisations' environment. Moreover, the organisations which have capabilities enable them to enhance R\&D activities driving them to improve their organisational culture. This culture characterised intensive knowledge by encouraging employees to realise and acquire new knowledge by providing specific training and development programmes that can help them be innovators. Further, the results elucidated that there is an impact of knowledge management on organizational ambidexterity and the result is consistent with other studies (e.g. Buyl et al., 2012; Oehmichen et al., 2017; Soto-Acosta et al., 2018). Thus, the organizations have a trend to generalize the knowledge within the organization by motivating the employees to diversification knowledge sources. Knowledge can be transferred into the internal organization's environment in order to create influential knowledge culture that helps to provide and share new skills and experiences which can perform to develop new products and services. Therefore, the organizations are continuously seeking to identify new ideas from both internal and external environment and applying new technologies. Furthermore, seizing the opportunities to improve products and services increases quality and improves operations activities in order to achieve effectiveness and efficiency in processes which can lead to cope with the competitors and building a competitive advantage. Based on the previous discussion and the results of the study, knowledge management mediates the relationship between strategic capabilities and organizational ambidexterity. Hence, the organizations which have strategic capabilities can be more flexible and rapid to identify and acquire new knowledge that exist in the business environments. Moreover, utilizing acquired knowledge capabilities enhance the abilities to reach customers' needs, as well as to provide creative products and services in order to achieve customer's loyalty. 


\section{Managerial Implication}

This study aimed to examine the impact of strategic capabilities on organisational ambidexterity, as well as the mediating role of knowledge management between these variables. Based on the results obtained, the decision-maker can adopt strategic capabilities by emphasising on building a good relationship with their suppliers to improve the flexibility of their processes, as well as enhancing their relationship with customers which enable the organisation to identify the changing on their customers' wants. Moreover, it helps activating the R\&D processes to build creative strategies in order to achieve their goals.

\section{Limitations and direction for future research}

Although this research provided some contributions to the literature, it has several confessed limitations that should be solved in future research. First, this research was performed in banking sector as a research population. Hence, the obtained results of this research should be used guardedly when attempting to generalizations into all sectors. To accurate generalization, future studies should be performed in other sectors such as health, insurance, and industrial. Secondly, the research sample size was small and limited for the target sector size, as well as this sample is comparatively homogeneous, and belongs to analogous cultures. Therefore, future studies can be executed in another geographic areas, or to make a comparative study between two different geographic areas. Finally, it is proposed that further studies could examine other variables related to strategic capabilities such as market orientation, entrepreneurship, innovative orientation by using samples from another sector.

\section{References}

Abbas, J., \& Sağsan, M. (2019). Impact of knowledge management practices on green innovation and corporate sustainable development: A structural analysis. Journal of Cleaner Production, 229, 611-620.

Abuzyead, Z.A., \& Sherif, S.F. (2017). The impact of the implementation the concept of knowledge management on security crisis management. Review of Public Administration and Management, 5(02). DOI: 10.4172/2315-7844.1000216.

Adil, H., al-Baghdadi Haidar, J., \& Al-Jobori, O. (2015) The Influence of organizational ambidexterity to achieve strategic flexibility an analytical comparative study between of Zain \& Asia cell communications companies in Iraq. Business and Economy, 1(1), 17-32.

Agyapong, A., Ellis, F., \& Domeher, D. (2016). Competitive strategy and performance of family businesses: moderating effect of managerial and innovative capabilities. Journal of Small Business \& Entrepreneurship, 28(6), 449-477.

Ahuja, G., \& Morris Lampert, C. (2001). Entrepreneurship in the large corporation: A longitudinal study of how established

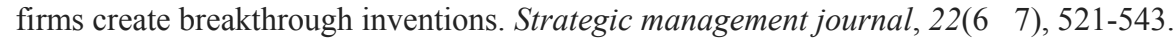

Alavi, M., \& Leidner, D.E. (2001). Knowledge management and knowledge management systems: Conceptual foundations and research issues. MIS Quarter 25(1), 107-136.

Al-Hawary, S. I. S., \& Alwan, A. M. (2016). Knowledge management and its effect on strategic decisions of Jordanian Public Universities. Journal of Accounting-Business \& Management 23(2), 24-44.

Alias, N.K., Mansor, A.N., Rahman, A.A., Ahmad, A.R., \& Samsudin, A.Z.H. (2018). The impact of knowledge management towards employee's job satisfaction. International Journal of Academic Research in Business and Social Sciences, 8(9), 245-265.

Assudani, R.H. (2008). What does it mean to manage 'knowledge': implications for the strategic management of knowledge in firms. International Journal of Management and Decision Making, 9(6), 646.

Atuahene-Gima, K. (2005) Resolving the capability-rigidity paradox in new product innovation. Journal of Marketing, 69(4), 61-83.

Barros, I., Hernangómez, J., \& Martin-Cruz, N. (2016). A theoretical model of strategic management of family firms. A dynamic capabilities approach. Journal of Family Business Strategy, 7(3), 149-159.

Baskerville, R., \& Dulipovici, A. (2006). The theoretical foundations of knowledge management. Knowledge Management Research \& Practice, 4(2), 83-105.

Bernard Nielsen, B. (2005). Strategic knowledge management research: tracing the co evolution of strategic management and knowledge management perspectives. Competitiveness Review 15(1), 1-13.

Birkinshaw, J., \& Gupta, K. (2013). Clarifying the distinctive contribution of ambidexterity to the field of organization studies. Academy of Management Perspectives, 27(4), 287-298. Bower, J.L., \& Paine, L.S. (2017). Managing for the Long Term. Harvard Business Review Spotlight, June 2017, 20.

Buyl, T., Boone, C., \& Matthyssens, P. (2012). The impact of the top management team's knowledge diversity on organizational ambidexterity: A conceptual framework. International Studies of Management \& Organization, 42(4), 8-26.

Carraresi, L., Mamaqi, X., Albisu Aguado, L. M., \& Banterle, A. (2012). Strategic capabilities and performance: an application of resource-based view in Italian food SMEs. Universitat Bonn-ILB Press.

Cheah, J., Amran, A., \& Yahya, S. (2019). External oriented resources and social enterprises' performance: the dominant mediating role of formal business planning. Journal of Cleaner Production, 236, 117693.

Čirjevskis, A. (2019). The role of dynamic capabilities as drivers of business model innovation in mergers and acquisitions of technology-advanced firms. Journal of Open Innovation: Technology, Market, and Complexity, 5(1), 12.

Cummings, J. L., \& Teng, B. S. (2003). Transferring R\&D knowledge: the key factors affecting knowledge transfer success. Journal of Engineering and Technology Management, 20(1-2), 39-68.

Day, G. S. (1994). The capabilities of market-driven organizations. Journal of Marketing, 58(4), 37-52. 
DeSarbo, W. S., Anthony Di Benedetto, C., Song, M., \& Sinha, I. (2005). Revisiting the Miles and Snow strategic framework: uncovering interrelationships between strategic types, capabilities, environmental uncertainty, and firm performance. Strategic Management Journal, 26(1), 47-74.

Di Benedetto, C. A., \& Song, M. (2003). The relationship between strategic type and firm capabilities in Chinese firms. International Marketing Review, 20(5), 514-533.

Dimitriades, Z.S. (2005). Creating strategic capabilities: organizational learning and knowledge management in the new economy. European Business Review 17(4), 314-324.

Donate, M. J., \& de Pablo, J. D. S. (2015). The role of knowledge-oriented leadership in knowledge management practices and innovation. Journal of Business Research, 68(2), 360-370.

Eisenhardt, K. M., \& Martin, J. A. (2000). Dynamic capabilities: what are they?. Strategic Management Journal, 21(10 11), 1105-1121.

Fu, N., Flood, P. C., \& Morris, T. (2016). Organizational ambidexterity and professional firm performance: The moderating role of organizational capital. Journal of Professions and Organization, 3(1), 1-16.

Ghaffari, H., Rafeie, M., \& Ashtiani, A. (2012). Quality open higher education via knowledge management. Journal of Basic and Applied Scientific Research, 2(2), 1787-1792.

Gilaninia, S., Rankouh, M. A. A., \& Gildeh, M. A. P. (2013). Overview on the importance of organizational learning and learning organization. Journal of Research and Development, 187(941), 1-6.

Guo, R. (2019). Effectuation, opportunity shaping and innovation strategy in high-tech new ventures. Management Decision 57(1), 115-130.

Hao, S., \& Song, M. (2016) Technology-driven strategy and firm performance: Are strategic capabilities missing links? Journal of Business Research 69(2), 751-759.

Helfat, C.E., \& Peteraf, M.A. (2009). Understanding dynamic capabilities: progress along a developmental path. Strategic Organization, 7(1), 91-102.

Hill, C.W.L., \& Jones, G.R. (2010). Strategic Management Theory: An Integrated Approach. 9th ed. Mason, OH: SouthWestern/Cengage Learning.

Jang, S. H. (2013). The offensive framework of resource based view (RBV): Inhibiting others from pursuing their own values. Journal of Management and Strategy, 4(1), 62.

Hughes, M. (2018). Organisational ambidexterity and firm performance: burning research questions for marketing scholars. Journal of Marketing Management, 34(1-2), 178-229.

Hughes, M. (2018). Organisational ambidexterity and firm performance: burning research questions for marketing scholars. Journal of Marketing Management, 34(1-2), 178-229.

Javidan, M. (1998). Core competence: What does it mean in practice? Long Range Planning 31(1), 60-71.

Johnson, G., Whittington, R., \& Scholes, K. (2017). Exploring Strategy. 11 ed ed., New York: Pearson.

Khyzer Bin Dost, M., Rehman, C., Gilaninia, S., Bte Ismail, K., \& Wasim Akram, M. (2018). The impact of knowledge management's practices on supply chain performance of the dairy sector in Central Punjab: a mediating role of decentralization. Economic research-Ekonomska istraživanja, 31(1), 290-312.

Kimosop, J., Korir, M., \& White, M. (2015). Strategic capabilities as determinants of firm performance in women-owned entrepreneurial ventures in Nairobi, Kenya. African Journal of Education, Science and Technology 2(2), $27-41$.

Kimosop, J., Korir, M., \& White, M. (2016). The moderating effect of demographic characteristics on the relationship between strategic capabilities and firm performance in women owned entrepreneurial ventures in Nairobi, Kenya. Canadian Journal of Administrative Sciences/Revue Canadienne des Sciences de l'Administration, 33(3), 242-256.

King, W.R. (2007). A research agenda for the relationships between culture and knowledge management. Knowledge and Process Management 14(3), 226-236.

Kotter, J.P. (1996). Leading Change. Boston, Mass: Harvard Business School Press.

Lado, A.A., Boyd, N.G., \& Wright, P. (1992). A competency-based model of sustainable competitive advantage: Toward a conceptual integration. Journal of Management, 18(1), 77-91.

Lee, K., Kim, Y., \& Joshi, K. (2017). Organizational memory and new product development performance: Investigating the role of organizational ambidexterity. Technological Forecasting and Social Change, 120, 117-129.

Lubatkin, M. H., Simsek, Z., Ling, Y., \& Veiga, J. F. (2006). Ambidexterity and performance in small-to medium-sized firms: The pivotal role of top management team behavioral integration. Journal of management, 32(5), 646-672.

Malkawi, M. S., \& Rumman, A. A. H. A. (2016). Knowledge Management Capabilities and Its Impact on Product Innovation in SME's. International Business Research, 9(5), 76-85.

Mills, A. M., \& Smith, T. A. (2011). Knowledge management and organizational performance: a decomposed view. Journal of Knowledge Management, 15(1), 156-171.

Moran, P., \& Ghoshal, S. (1996, August). Value creation by firms. In Academy of Management Proceedings (Vol. 1996, No. 1, pp. 41-45). Briarcliff Manor, NY 10510: Academy of Management.

Novak, A. (2017). Knowledge management and organizational performance - Literature review. Technology, Innovation and Industrial Management, Poland, 2017, pp. 433-440. Management Challenges in a Network Economy.

Obeidat, B. Y., Hashem, L., Alansari, I., Tarhini, A., \& Al-Salti, Z. (2016). The effect of knowledge management uses on total quality management practices: a theoretical perspective. Journal of Management and strategy, 7(4), 18-29.

Oehmichen, J., Heyden, M. L., Georgakakis, D., \& Volberda, H. W. (2017). Boards of directors and organizational ambidexterity in knowledge-intensive firms. The International Journal of Human Resource Management, 28(2), 283-306. 
O’Reilly III, C. A., \& Tushman, M. L. (2008). Ambidexterity as a dynamic capability: Resolving the innovator's dilemma. Research in Organizational Behavior, 28, 185-206.

O'Reilly III, C. A., \& Tushman, M. L. (2013). Organizational ambidexterity: Past, present, and future. Academy of management Perspectives, 27(4), 324-338.

Panagopoulos, G. (2016). Aspects of Organizational Ambidexterity. Journal of Global Strategic Management, 1(10), 5-5.

Parnell, J. A. (2011). Strategic capabilities, competitive strategy, and performance among retailers in Argentina, Peru and the United States. Management decision, 49(1), 139-155.

Pervan, M., Curak, M., \& Pavic Kramaric, T. (2018). The Influence of Industry Characteristics and Dynamic Capabilities on Firms' Profitability. International Journal of Financial Studies, 6(1), 4.

Peng, M. Y. P., Lin, K. H., Peng, D. L., \& Chen, P. (2019). Linking Organizational Ambidexterity and Performance: The Drivers of Sustainability in High-Tech Firms. Sustainability, 11(14), 3931.

Ramadan, B. M., Dahiyat, S. E., Bontis, N., \& Al-Dalahmeh, M. A. (2017). Intellectual capital, knowledge management and social capital within the ICT sector in Jordan. Journal of Intellectual Capital, 18(2), 437-462.

Raymond, L., St-Pierre, J., Fabi, B., \& Lacoursière, R. (2010). Strategic capabilities for the growth of manufacturing SMEs: A configurational perspective. Journal of developmental entrepreneurship, 15(02), 123-142.

Rothaermel, F. T., \& Deeds, D. L. (2004). Exploration and exploitation alliances in biotechnology: A system of new product development. Strategic management journal, 25(3), 201-221.

Salunke, S., Weerawardena, J., \& McColl-Kennedy, J. R. (2019). The central role of knowledge integration capability in service innovation-based competitive strategy. Industrial Marketing Management, 76, 144-156.

Santoro, G., Thrassou, A., Bresciani, S., \& Del Giudice, M. (2019). Do Knowledge Management and Dynamic Capabilities Affect Ambidextrous Entrepreneurial Intensity and Firms' Performance?. IEEE Transactions on Engineering Management. DOI: 10.1109/TEM.2019.2907874.

Otto Scharmer, C. (2001). Self-transcending knowledge: sensing and organizing around emerging opportunities. Journal of knowledge Management, 5(2), 137-151.

Seyhan, M., Ayas, S., Sonmez U, \& Gurlu, Y. (2017) The relationship between strategic capabilities and competitive performance: The moderating role of internal cooperation. International Journal of Academic Research in Economics and Management Sciences 6(1), 146-161.

Shimizu, K., \& Hitt, M.A. (2004). Strategic flexibility: Organizational preparedness to reverse ineffective strategic decisions. Academy of Management Perspectives, 18(4), 44-59.

Smith, W. K., \& Tushman, M. L. (2005). Managing strategic contradictions: A top management model for managing innovation streams. Organization science, 16(5), 522-536.

Soto-Acosta, P., Popa, S., \& Martinez-Conesa, I. (2018). Information technology, knowledge management and environmental dynamism as drivers of innovation ambidexterity: A study in SMEs. Journal of Knowledge Management, 22(4), 824-849.

Spillan, J. E., Parnell, J. A., Koseoglu, M. A., \& Akdeve, E. (2018). Strategic capabilities, niche strategy orientation and performance: a four-nation assessment. International Journal of Business Performance Management, 19(4), $427-449$.

Sulphey, M. M. (2019). Could the Adoption of Organizational Ambidexterity Have Changed the History of Nokia?. South Asian Journal of Business and Management Cases, 8(2), 167-181..

Takahashi, A. R. W., \& Sander, J. A. (2017). Combining institutional theory with resource based theory to understand processes of organizational knowing and dynamic capabilities. European Journal of Management Issues, 25(1), 43-48.

Teece, D. J. (2014). A dynamic capabilities-based entrepreneurial theory of the multinational enterprise. Journal of International Business Studies, 45(1), 8-37.

Torabi, M. H. R., Kyani, A., \& Falakinia, H. (2016). An investigation of the impact of knowledge management on human resource performance in management of Keshavarzi bank branches in Tehran. Procedia-Social and Behavioral Sciences, 230, 471-481.

Trivellas, P., Akrivouli, Z., Tsifora, E., \& Tsoutsa, P. (2015). The impact of knowledge sharing culture on job satisfaction in accounting firms. The mediating effect of general competencies. Procedia Economics and Finance, 19, 238-247.

Tzortzaki, A. M., \& Mihiotis, A. (2014). A review of knowledge management theory and future directions. Knowledge and Process Management, 21(1), 29-41.

Wadhwa, A., \& Kotha, S. (2006). Knowledge creation through external venturing: Evidence from the telecommunications equipment manufacturing industry. Academy of Management Journal, 49(4), 819-835.

Wenger, E., McDermott, R. A., \& Snyder, W. (2002). Cultivating communities of practice: A guide to managing knowledge. Harvard Business Press.

Ye, X., Ma, L., Feng, J., Cheng, Y., \& Liu, Z. (2018). Impact of Technology Habitual Domain on Ambidextrous Innovation: Case Study of a Chinese High-Tech Enterprise. Sustainability, 10(12), 4602.

Yu, X., Chen, Y., Nguyen, B., \& Zhang, W. (2014). Ties with government, strategic capability, and organizational ambidexterity: evidence from China's information communication technology industry. Information Technology and Management, 15(2), 81-98.

Yuliansyah, Y. (2018). Strategic Performance Measure, Innovativeness, Enterpreuneurship and Strategic Outcomes. Jurnal Ilmiah Akuntansi dan Bisnis, 197-206.

Zgarni, A. (2019). Cooperation or Coopetition Strategy: What is the Best Strategy Face to Competition'Intensity and Strategic Capabilities?. International Review of Management and Marketing, 9(5), 114. 
(C) 2020 by the authors; licensee Growing Science, Canada. This is an open access article distributed under the terms and conditions of the Creative Commons Attribution (CC-BY) license (http://creativecommons.org/licenses/by/4.0/). 